\title{
Innovation, Competition and Growth: Evolving Complexity or Complex Evolution
}

\author{
J. Stanley Metcalfe
}

ESRC Centre for Research in Innovation and Competition, The University of Manchester, UK

\section{Maria da Graça Derengowski Fonseca}

Instituto de Economia, Universidade Federal do Rio de Janeiro, Brasil

Ronald Ramlogan*

ESRC Centre for Research in Innovation and Competition, The University of Manchester, UK

ABSTRACT

This paper reports on the initial investigation into an evolutionary adaptive account of economic growth, innovation and competition. It starts from the premise that the economy is a system comprising multiplicity of agents, diverse in abilities and capabilities, interacting, adapting, reacting and constantly modifying the patterns on structures that they help to create.

Two themes in special are explored in this context. The first it is enterprise as the primum mobile of modern capitalist economies. The second relates to the importance of the economic growth as an emergent phenomenon. The transformation processes involved can be broken down into three elements: micro-diversity, selection processes and development processes. It is the manner of interdependence between these three elements that defines the relation between innovation, growth and competition.

We explore these issues in a model of growth whose forms differ in three dimensions: efficiency, investment behavior and processes of cost reducing innovation. The dynamics of Fisher's principles are explored in this context. The main result of this paper can be summarized as being a critical assessment of the knowledge foundations of endogenous growth theory, a clear

\footnotetext{
Please address comments to the corresponding author's e-mail:ronnieramlogan@man.ac.uk
} 
statement of the core elements in an evolutionary adaptive theory of growth and the analysis of economic growth through the use of replier dynamic processes.

KEYWORDS | Adaptive Complex Systems, micro-diversity, selection processes, competition, growth and emerging phenomena, information and knowledge.

JEL-Code | 01 Economic Development; 012 Microeconomic Analysis of Economic Development; 03 Technological Change; 033 Technological Change: Choices and Consequences.

\section{RESUMO}

Este artigo constitui-se numa investigação fundada na visão evolucionista sobre o crescimento econômico, inovação e competição. Nosso ponto de partida é a idéia de que o sistema econômico é composto por múltiplos agentes, diversos em habilidades e capacidades, interagindo e reagindo uns com os outros de forma a se adaptar ao ambiente em que estão inseridos. Neste processo, os agentes econômicos acabam por modificar os padrões de comportamento e as estruturas que eles próprios ajudaram a criar.

$\mathrm{O}$ artigo está construído em torno de duas idéias principais. A primeira é a de que o processo de tomada de decisões deve ser analisado através do conjunto de regras e rotinas que os agentes econômicos - em particular, as empresas - dispõem para decidir qual o curso de ação que devem tomar. Este tratamento permite recuperar a questão da micro-diversidade e da relevância de padrões de conduta. A segunda idéia está relacionada à importância do crescimento econômico como um fenômeno emergente. Como tal, os processos de transformação podem ser divididos em três elementos: processos de seleção, processos de criação de novidades (micro-diversidade) e processos de desenvolvimento.

A forma de interdependência entre estes elementos vai ajudar a definir a própria relação entre inovação, crescimento e competição. No contexto do artigo, a questão-chave está na especificação da concorrência como um processo de seleção. Para avaliar o crescimento e desenvolvimento de categorias relevantes dentro das populações tomamos como base os princípios de Fisher e seus desdobramentos nas equaçōes de replier dynamics. Acreditamos que o artigo possa ajudar a esclarecer os elementos centrais presentes na teoria evolucionista do crescimento endógeno, estabelecendo seus fundamentos no processo de conhecimento.

PALAVRAS-CHAVE | Sistemas complexos adaptativos, micro-diversidade, processos de seleção, concorrência, crescimento e fenômenos emergentes, informação e conhecimento.

Código JEL | 01 Desenvolvimento Econômico; 012 Análise Microeconômica do Desenvolvimento; 03 Mudança Tecnológica; 033 Mudança Tecnológica: Escolhas e conseqüências. 


\section{Introduction}

In this paper we report on our initial investigations into an alternative account of economic growth, innovation and competition. It is one that is compatible with the development of ideas in relation to evolving, adaptive systems. Indeed, we start from the premise that the economy is an adaptive evolving system comprising of multiple agents diverse in abilities and capabilities, interacting, adapting, reacting and constantly modifying the patterns and structures that they help create. And they do that on the basis of sets of internal rules that are modified and refined in the process of interaction. We believe that this approach offers the promise of new theoretical insights of economic processes, suggests new foci for empirical enquiry and also, new opportunities for the modelling of adaptive processes based on computational methods. (Saviotti,1996, Malerba et al,1999, Winter, et al, 2000, Ebersberger et al, 2000) We also believe that there are strong policy and strategic implications to this approach that we intend to develop in the future.

There are two clear themes that we wish to convey to the reader. The first is the importance of enterprise as the primum mobile of modern capitalist economies. To treat enterprise seriously, we argue, there is a requirement for the tools and methods of an adaptive, evolutionary approach to economic growth. The second relates to the importance of depicting economic growth as an emergent phenomenon, in which the focus is on the creation of patterns through interaction, with these patterns being created at different levels of interaction.

The focus of our enquiry turns on the process of economic transformation. We suggest that it is transformation that enables growth and that the process of economic transformation is an evolutionary process. As all evolutionary processes, it can be broken down into three elements: variety or microdiversity of agent behaviors; selection processes that transform that diversity into patterns of economic change; and, development processes that generate and regenerate that behavioral variation. It is the manner of interdependence between these three elements that defines any particular process of economic transformation.

Of course economic transformation has qualitative and quantitative dimensions and the interaction between the two is central to the evolutionary 
story. The qualitative dimension is closely connected with the process of innovation and is reflected in the introduction of 'new' and the withdrawal of 'old' economic activities. The quantitative dimension cannot be separated from ongoing processes of structural change in the economy. We sketch in this paper an argument to the effect that the link between the two is provided by a dynamic theory of innovation and competition as an evolutionary adaptive process.

We believe that without a particular hypothesis on development, the evolutionary framework is seriously deficient. Evolution and adaptation cannot be reduced simply to a matter of variety and selection. The generation of variety must also be explained and we do this through the hypothesis of a development process. Through the development process we have innovation in products and methods of production, and through the selection process, the continuing change in the relative importance of the different activities. Then, the link between transformation and growth depends on whether 'better' ways of satisfying economic needs increase in relative importance over time.

Novelty, or more precisely, the creation of novel economic activities plays a particularly prominent role in the approach that we pursue. We argue that the primary dynamic element in economic transformation is the generation of new business conjectures, theories and models of profitable activity that are to be tested in the market place. One asks of such a process, 'How creative is it?', 'What bounds does it place on the generation and trial of novel conjectures?', 'What properties does it have as an experimental system?' (Eliasson,1996; Rosenberg,1992; Foss and Foss, 1999). This perspective is essentially a perspective on the conditions for the growth of business knowledge, broadly defined; that practically useful knowledge that underpins the productive transformation of materials, energy and information into valued goods and services. As such it is bound to have a close affinity with the conditions for the growth of knowledge more generally and the essentially open-ended way in which all the knowledge is developed. There is much more to economic growth than formal science and technology and our analysis recognises this.

The institutional framework of the economy is extremely important in this approach. Selection processes in capitalism are essentially market-based processes and the function of markets is to simultaneously coordinate and value different activities. Prices of outputs and inputs are formed through coordination 
and these prices determine the profitability of the underlying theories of business. However, the institutions of the market are not given naturally. Markets are costly to establish and operate, they operate by sets of rules regarding to standards and conventions of doing business and they are ruled either by law or by informal practice. Most markets reflect the interaction between public and private interests.

Other institutions are equally relevant for the development process. The growth of knowledge depends on the interaction between organizations in the public and private domains that generate, store and communicate knowledge. These systems reflect the division of labor in the growth and application of knowledge between organisations and disciplines and, within these distributed processes of innovation, companies play the unique combining role of gathering and bringing together multiple kinds of knowledge to practical effect. Now these higher order institutions and organizations can also be said to evolve by processes of variation, selection and development so that the transformation of the economy involves evolution within its institutional structure and evolution of that structure. In this way we can begin to unravel the interaction between different levels of evolution in the economy. We do not believe it is possible to comprehend the transformation and growth of the economy without a clearly articulated account of how its institutional framework evolves over time. Competition is essential to this story in terms of the manner institutions are constructed and in terms of the innovation-growth dynamic. However, the competition, as a process of change, not competition as a market structure that matters in the evolutionary view-point. Schumpeter expressed this as a process of creative destruction and this perspective raises very interesting issues in relation to what is being sustained in the process of economic growth.

\section{The theory of economic growth}

It will be useful to begin with a sketch of the established theory of economic growth as a basis for explaining why an evolutionary adaptive approach has a great deal to offer. Until recently growth theory had two relevant attributes. First, it was not a theory of the rate of economic growth but rather a theory of the properties of an aggregate economy growing at an exogenous rate. Essentially this theory had been constructed to explain various stylized facts of the growth 
process including the (alleged) continuous over time of the income's distribution and the productivity of capital. Secondly, the main factor determining the rate of growth was the rate of technical progress, ultimately linked to the growth of new knowledge. Studies of residual productivity had established this fact beyond question despite the attempt to eliminate the residual by more refined and theoretically consistent ways of measuring the inputs of factor services. The residual was an embarrassment to prevailing theories of growth and never escaped from Abramovitz's labelling of it as a 'coefficient of ignorance'. However, in the subsequent process of refinement two questions became confused. The first is the extent to which we can measure accurately the shift in a production function by distinguishing between shifts and movements around it (Nelson, 1973). The second is the well separated question of the contribution that is made to economic growth by technical progress. These two questions do not have the same answer. Indeed in an economy that is growing steadily with a constant capital: output ratio, all of the measured growth in output per person employed is the consequence of technical progress and there is no independent growth contribution of factor accumulation. Put simply, the residual measurement procedure underestimates the contribution of technical progress to economic growth. Movements around the production function only arise to the extent that the function also shifts over time, and, for capital accumulation to have an independent role, the saving ratio of the economy would need to vary over time. There appears to be little evidence in favour of this possibility (Prescott, 1998). This point was stated with perfect clarity by Usher (1980), namely 'no technical progress means no growth'.

Now the consequence of this is rather problematic. Economic growth is predominantly due to the growth of practical knowledge yet growth theory is silent in regards to the conditions under which applicable knowledge is increased. It is this lacuna that theories of endogenous growth are intended to fill. One of the most important sets of ideas in this regard has been developed by Charles Jones (Jones, 1995), and it is worth sketching his central argument. (See Appendix)

It is that the growth of the economy is driven by the growth of ideas and that in an economy growing at a steady rate the stock of ideas will also increase at a steady rate. To establish this growth rate Jones appeals to the idea of a production function for ideas, a concept first introduced by Machlup (1962). 
Underpinning this notion is the non-rival property of information, that an idea may be used any number of times in the production of goods and services, and more importantly, any number of times in the production of new ideas. At any moment in time there is a stock of ideas on which researchers can work, this stock defining a set of unsolved problems. Applying more research effort to this given stock eventually runs into diminishing returns, however, the output of new ideas arising from this effort also changes the remaining stock of problems to be solved. This lies in the dynamics of the idea of creation as an autocatalytic process, in which ideas beget ideas. This led Machlup to an interesting distinction between the discovery of new ideas that expand the stock of unsolved problems (agenda increasing ideas) and those that reduce the remaining stock of unsolved problems (agenda reducing ideas). Thus, today, advances in knowledge shift the productivity relations for tomorrow's research and so enhance the incentives to allocate resources to research. Jones works with the same framework by letting the rate of growth of ideas depend on current research effort and the prevailing stock of ideas, and then identifies the conditions under which the stock of ideas can grow at a constant rate. If such a rate exists, he shows that it will be proportional to the rate of growth of current research effort which he makes equal to the rate of growth of the population. The condition for the existence of such a steady state is that the elasticity relating the rate of growth of ideas to the prevailing stock of ideas is less than a unity in value, this corresponding to an agenda-reducing pattern of knowledge growth in Machlup's terms.

Now an important reason for spelling this out is that the Jones' approach, and indeed the orthodox approach to the growth of knowledge and the growth of the economy, is at the opposite end of the spectrum from the evolutionary adaptive framework discussed here. Why this is so is worth careful statement.

The first source of difference in the idea of ideas growing in a steady rate either in terms of themselves or in terms of their practical applicability. That knowledge feeds on knowledge is a perfectly sensible idea but that it does so at a constant geometric rate, seems particularly hard to swallow. That research effort may grow in aggregate at such a rate does not entail the steady growth of the output of that enquiry, an observation that is surely consistent with the uneven growth of science and technology over time let alone its uneven rate of 
application. Part of the problem here is in conceiving an aggregate stock of ideas. Are the ideas to be added, multiplied together, or aggregated in a combined fashion, in which case the stock grows faster than exponentially? Whatever the process of aggregation is, we still need the weights (prices) with which an idea in carbon chemistry, say, is so combined with an idea in the production of insurance services. It is not obvious what these weights are, and they certainly are not to be found in market prices. But then if ideas are disaggregated into more conformable groups we face another difficulty. Namely, if we let the rates of research effort to grow at the same rate for all classes of knowledge, a condition for steady growth on the input side, it will imply that all the different stocks of ideas cannot grow at the same rate, making it impossible to have steady growth on the output side. (See Appendix)

It seems clear that the source of these difficulties is two-fold, relating to the macroeconomic level of aggregation and to the notion of a steady rate of knowledge accumulation. Neither of these is compatible with the idea of growth as transformation since they exclude from consideration the most pervasive of all the stylised facts of economic growth, structural change. The fact that macro aggregates vary slowly over time does not imply that the underlying micro components also change slowly. Growth does not occur without persistent changes in the relative importance of products, methods of production, companies, industries, regions and whole economies, and these changes in structure are a consequence of the growth process. The steady aggregate growth that we observe is usually based on microeconomic turmoil. Such turmoil is not an inconvenience that hides the economic process like the shadows on the wall of Plato's cave, it is the process of growth. Economic, technological and business historians have long understood this elemental point, as have the group of scholars that sail under Schumpeter's banner, and those who are more explicitly evolutionary in their approach. Growth 'theorists' of the 1920's and 1930s, including Young (1928), Kuznets (1929) and Burns (1938) also understood this fact. Indeed, their theories of growth placed special emphasis on the uneven accumulation of knowledge in the economy.

To take these ideas on board requires that the macroeconomic approach to growth needs to be reinterpreted in radical fashion, in the light of the restless nature of capitalism. This is the conclusion drawn from the researches 
of a number of scholars who are working with detailed longitudinal data sets in the USA manufacturing economy. They have produced compelling evidence on the wide range of productivity differences even between firms in the same narrow industry, on the persistence of these differences over time, and on the corresponding importance of the changing relative importance of different companies and industries to the process of overall productivity growth (Foster et al., 1998; Bailey et al., 1992; Baldwin, 1995; Bartlesman and Doms, 2000). It is clear from this work that micro-diversity, in this case in relation to productivity and productivity growth, cannot be reduced to random fluctuations around a common productivity level and that there are a multiplicity of reasons for these differences between companies (Nelson, 1991, Harberger,1998). This supports the view of some management scholars on the idiosyncratic properties of the firm, each one, as it were, writes its own signature in the economic record (Metcalfe, 1996). To accommodate these findings requires a very different approach to the study of growth, an approach that is embodied in the evolutionary perspective.

The first casualty of the change in perspective is the macroeconomic approach to understanding growth. We can measure macro economically but to do so necessarily averages away the details that matter for comprehending the growth process. This is not at all a statistical matter of eliminating unnecessary detail to get to the essentials. Rather it is the micro-diversity of behaviors and of the coordination process in specific market contexts that defines the transformation process from which growth is a consequence. To put together the consequences is not the problem, which is to obscure the process generating them. Crucially this means that we must approach the study of growth in a 'bottom-up' not a 'top down' fashion. Indeed, any top-down approach precludes the study of emergent phenomena.

The second casualty is the resort to expressing arguments in terms of representative agents, or more precisely, uniform companies and households (Kirman 1992). Leaving aside the difficulty of how innovation is to be introduced without destroying the uniformity of behavior, the fundamental point is that behaviours that are representative in a statistical sense are emergent properties. Emergent properties are not attributes of individual agents but rather behavioral consequences that arise from the interactions between agents, and 
such interactions cannot be properties of the individual agents (Langlois, 1983, Blume and Durlaf, 2000). What is considered to be representative behavior, therefore, must be a product of the analysis not an assumption underpinning it. Consequently, representative behavior in a population of agents can evolve even when the underlying individual behaviors are constant. In a world of uniform agents this would, of course, be impossible. As we shall see, in the presence of diverse micro behaviors what is representative in any given context depends upon the manner in which the individual behaviors are coordinated by markets and other institutions. Notice that this gives an evolutionary, adaptive theory an inevitable non-reduction flavour, it is necessarily a rather sophisticated form of methodological individualism.

There is no more difficult concept to try and deal with in representative agent terms than that of the entrepreneur. Since entrepreneurs are agents of change, they cannot exist in equilibrium, the rewards they earn depend on the economy being far from equilibrium, and the very notion of entrepreneurship it is tied to the introduction into the economy of novel behaviors. Clearly an evolutionary, adaptive account of the economy must give entrepreneurship and enterprise a special place in its analysis. Indeed, the notion of entrepreneurial behavior is, we believe, an unavoidable component of any complexity based approach to the economy.

The final change in perspective is rather more difficult to handle for it involves the claim that the idea of economic equilibrium be abandoned. It involves the parallel claim that there is no attracting state to which the economy is converging over some temporarily indeterminate 'long-run'. Several fundamental issues need to be unravelled here. The first is that the dominant issue in economic organization is that of coordination, the equation in the market of plans to buy and sell in reference to a particular time period. There is nothing wrong in referring to this as a temporary equilibrium providing we do realise its transient nature. But it is far better to refer to it as a temporary order, for that is what coordination leads too, order not equilibrium (Loasby, 1999). Coordination, of course, occurs at many levels and we can distinguish between coordination within a market for a given class of products, coordination between these markets, and top level coordination of saving and investment in the capital market. The interlinking of these different levels of coordination 
shapes the process of transformation and maps onto corresponding levels of evolution. Indeed, coordination is central to the problem of emergence interpreted as the evolution of economic structure from within the system itself (Dooley and Corman, 2000).

The second fundamental issue relates to the process of the accumulation of knowledge. Knowledge does not accumulate out of context or of the passage of time. Therefore, much knowledge results from the conduct of the market process as suppliers and customers interact and learn what to produce and from whom to buy. To this extent much economically valuable knowledge is a product of coordination and can be expected to accumulate differently in different coordination systems. It is this fact which links evolutionary explanation with some Austrian approaches to economic evolution as a discovery process. It follows that every position of temporary order creates within it the conditions to change that order, and this is especially true for the knowledge accumulated in the pursuit of innovation. This is a point that Schumpeter was especially keen to emphasize, namely that the development of capitalism arises from within. It is reinforced when we recognize that all economic processes occur in real time and that the mere passage of time means experiencing events and thus, gaining new information. In both these counts it is particularly problematic try to posit some equilibrium economic state that is invariant to the motion towards it, for this is tantamount to holding knowledge (and the real time of human experience) constant while we get to equilibrium. This makes no sense to us other than as a formal way to avoid the problem. In short, when economies are out of equilibrium they stay out of equilibrium. But they always exhibit order and that order reflects, and might be measured in terms of processes of interaction, and the patterns of coordination that ensue. Notice that this point runs much deeper than that of path dependence of outcomes in the presence of positive feedback processes. It is the point made by Kaldor (1934) and it arises even when all production and marketing processes are of the constant returns to scale kind, in the conventional sense. One cannot have economic activity without a change of knowledge. In the modern economy, of course, this is reinforced by the practice of allocating a non-trivial portion of the economy's resources to the acquisition of knowledge and its embodiment in the population. 
Thus, in tying the growth of the economy to the transformations associated with the endogenous growth of practical knowledge we need to set up our thinking on economic growth in a quite different, non-aggregate way. This is the route of the evolutionary adaptive approach and we turn now to its major attributes. These are three in number: the assembly of aggregate relations from micro components in a bottom up fashion; the emphasis on competition as a process involving the coordination of diverse behaviors; and, the characterization of the economy as operating far from equilibrium. One immediate consequence of this is that no evolutionary, adaptive theory of economic growth would begin by framing the process in a top down fashion via some aggregate relation between input and output.

\section{An evolutionary core}

Evolutionary theories are naturally accounts of the rate and direction in which the world changes. They are theories of differential growth and decline in the absolute and relative numbers of designated entities. They are, as Winter has repeatedly emphasised, theories of becoming not of being. For the economist and economic historian, the development of evolutionary explanations of economic phenomena has provided a powerful set of ideas that make sense of the relation between innovation, competition and economic growth. By accepting that capitalism in equilibrium is a contradiction in terms, we must give prominence to the idea of transformation as flux, of growth as development.

What are the principal characteristics of evolutionary theories? This is not an easy question to answer as the synthetic theory of what constitutes an evolutionary process has been the topic of considerable development and controversy (Depew and Weber, 1995, 1999). The broad selectionist core has been challenged on the one side by claims in favour of contingency and stochastic drift and on the other by claims in favour of the new dynamics of self-organising and non-linear processes. Along with Depew and Weber we see these developments as an enrichment of the evolutionary approach that simultaneously needs to accommodate selection with chance and non-linear feedback dynamics. After all economies are composed of multiple agents 
interacting in a multiplicity of partially connected ways and subjected to a good deal of noise; precisely the conditions for complex, adaptive, evolutionary patterns of change.

In his recent survey of non-linear economic theories, Brock (1999), building on Arthur, Durlaf and Lane (1997) suggests that complexity involves the following: dispersed interactions, self organization without a guiding hand, the interlinking of hierarchies at different levels, perpetual novelty, continual adaptation, and, out of equilibrium dynamics. By contrast, the synthetic account of evolutionary processes emphasises only three elements. These are: the principle of variation, that members of a relevant population vary in characteristics that convey selective significance; the principle of heredity, that the characteristics of individual entities are copied over time by appropriate mechanisms; and, the principle of selection, that interaction between the entities in a specific environment implies that some entities have sets of characteristics better suited to their survival and growth in the population. Notice carefully that survival and growth are not characteristics of entities, rather they are consequences predicted by their involvement in a selection process. It is this confusion which so often lies beneath the really mistaken notion that selection theory is tautological (Sober, 1994).

Now the attributes claimed by Brock to define complex systems, map in a ready way onto the more traditional evolutionary triad. Perpetual novelty relates to the generation of variety and keeps selection processes far from equilibrium. Dispersed interaction is another way of defining a selection process, and interacting hierarchies captures in which point that selection (and development) can occur at multiple interdependent levels. Continual adaptation is the consequence of a variation selection process from which patterns of order emerge and are not imposed from on high, as it were. If this were correct, there would seem to be little incompatibility between the old synthesis and the new field of self-organizing complexity. However, the fruits of the interaction between these different approaches remain to be elaborated. Our conjecture is that the study of growth, innovation and competition will provide a suitable lens to do so.

The distinguishing feature of an evolutionary theory is that it concernes populations of entities and the associated measures of evolution relate to changes 
in the statistical properties of those populations (Metcalfe, 1998). That is to say they are concerned with the changing frequencies of particular behaviors. Philosophers call this a population approach and contrast it with a typological approach in which the focus is on ideal types. In this essentialist way of thinking all variations around the ideal types are accidental, they are inconsequential aberrations due to impermanent interfering forces. They are therefore, to be ignored. It is this style of reasoning that leads to the uniform agent and which is anathema to the evolutionist, as we explained above. For in population thinking, variety is not an interfering complication that hides the underlying reality it is the underlying reality and it is the prerequisite for a theory of change. It is for this reason that evolutionary theory is often equated with statistical theory (Horan, 1995); not in the probabilistic sense but rather in terms of being a theory of how the statistical moments of the population distribution evolve over time under the pressures of selection and development. Such moments, of course, are constructed from data on all the members of a population, they are descriptive aggregates, and they are not representative of any individual representing that entire population. Thus, the fundamental point about population thinking and selection is that deterministic processes give rise to statistical change. None of this is incompatible with stochastic variation in the characteristics of the underlying entities or in the working of the selection process. Indeed, the neutral theory of evolution is one in which characteristics that do not convey selective advantage drift stochastically over time. The two approaches are perfectly compatible.

It will be clear that the basic demarcation in evolutionary theory is between units of selection and the selection environment. The units of selection are entities whose selective characteristics are relatively stable over time to preserve the identity of the entities in question. In economic approaches the units are often specific business activities producing a particular set of products using particular methods of production. The selection environment is defined independently of the entities; it is the framework that evaluates the various entities and transforms their selective characteristics into selective advantage. In economic evolution this is usually specified as a form of market coordination process. This demarcation needs to be treated with care. What is the unit of selection at one level can be the selection environment at another level. Thus, for example, the company as unit of selection in the competitive process 
becomes the selection environment when we consider its internal development process and how it evolves over time. This is not a problem albeit it is an interesting challenge that enriches the evolutionary approach, since it brings into the frame the way in which selection environments are instituted. Equally enriching is the possibility that the units of selection do not treat the selection environment as a parametric given. Companies, for example, do devote considerable effort in constructing the selection environment in an advantageous way, as they do when establishing proprietary standards that become the market standard. Similarly, in pressing for particular taxes, tariffs or subsidies they seek to alter the selection process to their advantage. An evolutionary economic approach needs to recognize that selection environments are constructed by the actors within them and regulated by external actors; there is not natural givens, and this opens the possibility of treating the construction of selection environments as a 'higher evolutionary' process. Here there is a powerful connection with those economic-sociological literatures, beginning with Polanyi (1957), that emphasise the institutionalization and mutual embeddedness of economic and social processes.

There is another reason why an adaptive evolutionary approach to competition, innovation and growth differs from its biological counterparts. This lies in the role of the intentionality of human agency. Individuals behavings in the solitary moment of the present and selection can only be defined in relation to the present but this does not prevent memory of past selection outcomes and the anticipation of future ones shaping the selective characteristics of the relevant agents. Memory and expectation necessarily play a role in any explanation that depends on the creativity and novelty of agents. But clearly, such expectations cannot be rational in the global sense that all agents understand the workings of the economic process in the same way. Indeed, a moment's reflection allows us to see that having expectations different from others is central to the variety generating process. This is particularly important in relation to the formation of business strategies, for innovation and innovation strategy involves none other than a process of idiosyncratic expectation formation. In a world of heterogeneity, the rationality of expectations cannot equate to the uniformity of expectations. The point is to have a better model of the world than one's rivals, not to work with the same model of that world. 
It is vital in summarizing the points above to recognize that evolutionary explanations are not biological explanations and that evolutionary theory has its own logic independently of its field of application. It is a logic of micro diversity and interaction to generate patterns of change.

\section{Two-stage and three-stage processes}

This logic has often been elaborated as a two-stage process involving prior variation and subsequent selection (Mayr, 1982). As we shall see, this approach takes us a long way in evolutionary dynamics but it is so patently only a part of any evolutionary theory. The crucial step is to realize that any selection process destroys the variety of the existence on which it depends: as Lewontin expressed it, 'evolution consumes its own fuel'. Some account is needed not only of the initial amount of variety in a population, but of the replenishment of that variety over time. Otherwise evolution grinds to a halt.

The answer to this puzzle is provided by developmental processes, so that evolution becomes a three-stage scheme involving the generation and destruction of variety of behavior. This is particularly so for economic evolution, as Schumpeter's famous bon mot so succinctly characterized, and this has been and open-ended. This is why the future of economic systems is not predictable, their history is open-ended. As Marshall (1898) recognized, economic activity changes knowledge directly and indirectly and every change in knowledge opens up the conditions for changes in activity and thus further changes in knowledge, ad infinitum, and in quite unpredictable ways. Economic systems are necessarily 'restless', the clock can never be turned back (Foster, 1993) and these are features uniquely associated with the capitalist system of organization. Moreover, these systems are competitive not by virtue of their market structure but by virtue of the fact that every economic position is open to challenge while the generation of novelty becomes the means to mount those challenges.

Thus, what matters for the rate and direction of economic transformation is the correlation between processes of selection and development. It is not always the most profitable company or the largest company that comes up with the novel idea to transform an industry; often it is a company operating in another industry or on an entirely new venture. This is something that business, technological and 
economic histories make abundantly clear. However, how this correlation works out in any given context depends on the way that the development and selection processes have been instituted and a complete evolutionary account would explain these instituted characteristics, in terms of those higher order processes of variation, selection and development. It is here that an account of the role of policy and the state is of relevance and the corresponding boundary between public and private action is blurred. It is here also that the phenomena related to collaboration in the development process between companies and other organizations find their place.

What this account points too, is positive feedback in the relation between selection and development, moderated by a substantial element of noise. Development is autocatalytic in relation to selection, it is an open-ended process in which new information is the driving force that keeps the economy far from equilibrium. Economic transformation is open-ended precisely because the generation of information and its translation into knowledge is also autocatalytic and open-ended. This is why the future of economic systems is not predictable, their history is open-ended. As Marshall (1898) recognized, economic activity changes knowledge directly and indirectly and every change in knowledge opens up the conditions for changes in activity and thus further changes in knowledge, ad infinitum, and in quite unpredictable ways. Economic systems are necessarily 'restless', the clock can never be turned back (Foster, 1993) and these are features uniquely associated with the capitalist system of organization. Moreover, these systems are competitive not by virtue of their market structure but by virtue of the fact that every economic position is open to challenge while the generation of novelty becomes the means to mount those challenges. Thus, the self-organization of knowledge becomes an essential part of the evolutionary story. Popper (1985) is of help here, not least because of the clarity with which he argues that the accumulation of knowledge is an unfolding process in which the realisation of possibilities makes possible the specification of new possibilities. Since all knowledge is provisional we adhere to what we know until something better comes along and this is as true of business conjectures as it is of conjectures about the natural and man-made worlds. It is the fact that knowledge generates knowledge that links together selection and development to mark economic evolution as a positive feedback process. Complex, adaptive, evolutionary processes may provide the most promising way to capture this dynamic. 


\section{Growth theory and the replier dynamic}

Inn this section we consider one of the key elements in the formalization of an evolutionary process, that of the replier equation. This brings together the ideas of micro-diversity and selection process. Since Fisher (1930), this has become the principal tool for study of selection processes and there is an extensive literature on its properties (Michod, 2000; Frank, 1998). This works in terms of the statistical properties of the distribution of selective characteristics and provides the explanation of evolutionary change in terms of the population moments of this distribution. Even in a population in which the characteristics of the entities are fixed, there will be evolutionary change at the population level and this is the chief insight of replier analysis. Moreover, the replier process links directly to the idea of the competitive process with the units of selection being units of business, or companies, for short. Thus, the replier is embedded in the institutions of the market place and in the way that these stimulate and accommodate to economic change.

In terms of growth theory the replier also motivates the idea of differential interdependent rates of growth of the different entities in the population and differential growth leads us straight to structural change. Crucially, growth of an entity or any ensemble of entities is not to be conceived as a process of convergence to some attracting point; for the force of our previous discussion is that no such state may exist. Rather, the replier defines a distributional dynamics, in which the changing relative position of the entities depends upon how their particular selective characteristics are distributed around the current population averages. All the dynamic motion is contained in this distance from mean principle. These processes have a number of general characteristics:

- The population averages for each selective characteristic change over time in a way which depends on the distribution of each and of the other characteristics in the current population. This is the result called Fisher's Principle (Metcalfe, 1998).

- Whether or not the individual characteristic represent some optimising principle at the level of the entities, the evolution of the population as a whole does reflect an optimising principle (Kimura, 1958). Namely, that the rate of change of the appropriate population 
averages changes more rapidly with the replier dynamic than with any other process of selection. The consequence of this is that the more efficient are the market arrangements, the faster is the rate of evolutionary selection in the competitive process.

As a prelude to using the replier process in an illustrative model of innovation, competition and growth it will help to sketch the general method more formally.

Consider a set of entities fixed in number, each entity being described by a vector of selection characteristics $z$. These characteristics are intrinsic properties of the entities and let these be fixed for the moment. The entities constitute a population by virtue of the fact that they interact in a common selection environment and it is the experience of a common selective process that determines whether any entity is a member or not of this population. The process of interaction, values the selective characteristics and the values so obtained determine the rate of growth, $g_{i}$, in the scale or number of each entity in the population. At any point in time the structure of the population is described by the share of each entity, $s_{i}$, in the total population of entities.

Now consider some selective characteristic $x_{j}$ in the population. The mean value is defined by $\bar{x}_{j}=\sum s_{i} x_{i j}$ and the rate of change of this mean value is

$$
\frac{d \bar{x}_{j}}{d t}=\sum_{i} \frac{d s_{i}}{d t} x_{i j}
$$

Now

$$
\frac{d s_{i}}{d t}=s_{i}\left(g_{i}-g\right)
$$

where $g=\sum s_{i} g_{i}$ is the rate of increase in the total population. Whence, we find the first statement of Fisher's Principle that

$$
\frac{d \bar{x}_{j}}{d t}=\sum_{i} s_{i}\left(g_{i}-g\right) x_{i j}=C_{s}\left(g, x_{j}\right)
$$

The covariance (using population shares as weights) between the characteristic in question and the growth rates of the entities measures the rate 
of change of the population average value of that characteristic. That is to say, evolution equates to correlation, and the theory of selection explains how this correlation is determined and how it changes over time. Notice how a theory of differential growth its built into this analysis from the outset. Any entity that is growing more quickly than the population average will be increasing in relative importance and its pattern of selective characteristics will have a greater influence on the relevant population averages. The average entity, the representative entity in terms of growth rates if you wish, has a constant relative importance in the population. These links between differential growth and structural change lead to a particular version of Fisher's Principle for the growth rates. From the definition of $g$ is follows that

$$
\begin{aligned}
\frac{d g}{d t} & =\sum_{i} \frac{d s_{i}}{d t} g_{i}+\sum_{i} s_{i} \frac{d g_{i}}{d t} \\
& =\sum_{i} s_{i}\left(g_{i}-g\right) g_{i}+\sum_{i} s_{i} \frac{d g_{i}}{d t} \\
& =V_{s}(g)+\sum_{i} s_{i} \frac{d g_{i}}{d t}
\end{aligned}
$$

where $V_{s}(g)$ is the variance (weighted by the shares $s_{i}$ ) of the growth rates in the population. If the individual growth rates are constant this gives Fisher's Fundamental Law that

$$
\frac{d g}{d t}=V_{s}(g)>0
$$

so that selection always works to increase the population growth rate, in his terms the average fitness of the population. If, by contrast, the average growth rate is fixed by some hypothesis, then

$$
\sum s_{i} \frac{d g_{i}}{d t}=-V_{s}(g)<0
$$

On average the growth rates of the individual entitles must be declining over time, corresponding to what an earlier generation of growth economists (Kuznets, 1929; Burns, 1934) called retardation of growth.

Now the force of the three stage approach to evolution is that the replier alone it is an incomplete account of the evolutionary process. What is missing 
is an account of how the selective characteristics are created and recreated over time. How does development fit into this picture? In terms of the average value for characteristic $x_{j}$ we simply add in a second development term

$$
\frac{d \bar{x}_{j}}{d t}=\sum_{i} \frac{d s_{i}}{d t} x_{i j}+\sum s_{i} \frac{d x_{i j}}{d t}
$$

so that the rate of change of the average is the sum of the selection and development effects. (In discrete terms, of course, there would also be a third, interactive term.)

Taken together, selection and development provide the backbone of an economic theory of innovation, competition and growth.

\section{Innovation, competition and growth}

The questions for an evolutionary explanation of growth should be clear by now. How an analysis it is based upon selection and development to be translated into a theory of economic transformation? How are we to give prominence to the ideas of micro-diversity, competitive processes and innovation? No doubt there are many ways to answer these questions, but they will all have broadly the same structure if they are based on evolutionary ideas. Here is such a sketch, like all sketches it highlights parts of the terrain and not others and it works with a particular level of resolution. Clearly much is left out but the purpose is to illustrate the method not to provide a comprehensive statement of evolutionary growth.

As with all agent-based models a dichotomy is drawn between the agents and the environment in which they interact. In this case the agents in focus are business units, companies, for short, producing a given product. Each company is characterized by a bundle of decision routines, the capabilities to articulate those routines and a particular strategic intent. These routine bundles may or may not be optimal in some sense; if they are, they are locally optimal. What matters is not optimality per se but micro-diversity of the routine bundles. The articulation of these bundles it is captured in three attributes of the firm: the efficiency with which it produces the given product; the rate at which it invests to expand capacity; and, the rate at which it innovates to improve its 
efficiency. It is the specification of the rules that corresponds to the limited degree of agent adaptability to changes in the environment.

Let the firms have the same capital-output ratio, $b$, but let them differ in their unit labor requirements, $a_{i}$. If the wage is $w$ and the cost of capital is $R$ we can write unit costs as $h_{i}=w a_{i}+b R$. Let $s_{i}$ be the share of the company's output in total output and let $e_{i}$ be the corresponding share of total employment. Since labor productivity is $q_{i}=1 / a_{i}$ it follows that $e_{i} \bar{a}_{s}=a_{i} s_{i}$ or equivalently that $e_{i} q_{i}=\bar{q}_{e} s_{i}$, where $\bar{a}_{s}=\sum s_{i} a_{i}, \bar{q}_{e}=\sum e_{i} q_{i}$ and $\bar{a}_{s} \bar{q}_{e}=1$. The shares $s_{i}, e_{i}$ are measures of the structure of the economy, and their changes provide evidence for the rate and direction of economic transformation. The values of $a_{i}$ will depend on technology and organization at the level of the company, they reflect the disparities in knowledge across the companies but they do not measure these differences in knowledge.

The companies produce and sell in a market environment, a set of instituted practices for disseminating information about rival offers, and demands and the associated terms of trade. In this context, the companies set prices and they do so by taking into account the effectiveness of the market in diffusing knowledge on prices. In a perfect market, there is no latitude a company must set the same price as all its rivals. As the market institutions become less effective at disseminating information so the latitude to set individual prices increases. In each case we need a price setting rule, a non-trivial requirement. For clarity, we assume this rule is such that each company sets prices to equate the rate of growth of its market with the rate of growth of its capacity. We call these 'normal' prices.

The market environment plays two interdependent roles in this account. First, it values the activities of the companies. By constraining the prices set, it establishes a distribution of profitability in relation to the underlying distribution of the routine bundles of the companies. Secondly, it is the context for market selection, the process by which the companies grow at different rates capturing market share at different rates.

We capture this process by a standard procedure (Phelps and Winter,1971; Iwai, 1974; Metcalfe, 1998) in which the 'customers' in the market are mixing at random (a homogeneous market with no geographic or other niches), comparing prices, $p_{i}$, and shifting demand when they obtain information of 
a company setting a lower price. The consequence is that the growth of the particular market for any company depends on how its price compares with all the other prices set by rivals. This enables to write the rate of growth of demand for its output, $g_{i}$, as

$$
g_{i}^{\prime}=g_{D}+\delta\left[\bar{p}_{s}-p_{i}\right] ; \quad \bar{p}_{s}=\sum s_{i} p_{i}
$$

where $g_{D}$ is the overall growth rate of the market, and $\delta$ is the market selection coefficient capturing the speed at which demand shifts between companies, when they set different prices. A perfect market corresponds to $\delta=\infty$, and the companies set identical prices. A world of isolated monopolies corresponds to $\delta=0$, and the companies set normal prices in relation to their desire to grow.

The growth in the capacity of each company, $g_{i},{ }_{i} s$ governed by its investment function, relating its desired expansion to its profitability. Formulate this as

$$
\left(\frac{I}{Q}\right)_{i}=b g_{i}=-\phi_{i}+\mu\left[p_{i}-h_{i}\right] p_{i}>h_{i}=0 \text {, otherwise }
$$

The ratio, $\phi_{i} / \mu$, measures the minimum margin required before the company investment. It is not essential to what follows that $\mu$ is assumed the same, it simply makes the exposition more straightforward. The coefficient $\phi_{i}$ measures the willingness to invest, which is smaller the greater is $\phi_{i}$.

The final dimension of the company stands in relation to its innovative performance, the visible sign of the change of its knowledge. Innovation is focused on unit labor requirements which reflect the organization of production which in turn, we take to depend on the scale of the company's activities. In short, scale influences organization and organization influences efficiency. To capture this aspect of the development of the company we adopt a simple technical progress function relating the rate of decline in unit labor requirements to the growth rate of capacity. Thus,

$$
-\frac{d}{d t} \log a_{i}=\frac{d}{d t} \log q_{i}=\alpha_{i}+\beta g_{i}
$$


If $0<\beta<1$, we have a positive feedback process or increasing dynamic returns. If $\beta<0$ we have decreasing dynamic returns and growth harms efficiency. Clearly, there is a link here with Edith Penrose's (Penrose, 1958) theory of the company and the relation between the rate of growth and the accumulation of capabilities. The parameter, $\alpha_{i}$, simply captures all other idiosyncratic influences on the company's innovating performance.

Taking (1), (2) and (3) together, we have all the elements of an evolutionary growth model. There is micro-diversity, variety, in respect of, productivity, investment behavior and innovation. There is a selection within a competitive process produced by the interaction of (1) and (2) within the given population of companies, and there is a development as captured by the technical progress functions (3). Moreover, and this is crucially important, selection establishes a distribution of growth rates which implies a distribution of innovation rates to redefine the distribution of unit labor requirements and unit costs. Thus, some of the selective characteristics of the company evolve through the interaction of development and selection. It is therefore, interdependence that is crucial to an adaptive evolutionary account of growth.

To understand how this works out it is useful to divide the argument into two parts corresponding to the process of selection and development.

\section{7 - Selection}

If we combine together (1) and (2) with the assumption of a given number of companies, we can work out the dynamics of selection and the patterns of economic transformation that follow. At any point of time the companies fall into three possible categories. First, we have the profitable companies, $p_{i}>h_{i}$, setting normal prices to grow at a rate determined by the market process and their investment rules. A second possible group of companies just break even, $p_{i}=h_{i}$, they do not invest and they use the existing capacity to meet whatever demand there is. These are the marginal companies. Finally, there are the non-feasible companies that make losses, $p_{i}<h_{i}$, and we assume that they have abandoned production. It simplifies matters greatly for present purposes to focus only on the first group of dynamic companies. The cost is that we cannot consider exit rules or entry behavior but to do so 
would take us well beyond the current remit of this paper (Metcalfe, 1998; Calderini and Metcalfe, 2000).

It is useful now to define two kinds of micro-diversity. Primary diversity relates to the intrinsic characteristics of the company, the selection characteristics, defined in terms of input productivity, investment and innovation behaviors. These are the data for the selection process. Secondary diversity relates to those phenomena that are emergent in the coordination process in the market. The growth rates, prices and profit margins, all fall in this category. They are not intrinsic attributes of any company but rather, arise from a 'higher level' process of interaction within the population of companies.

Combining (1) with (2) we can establish for each from the relation between its growth rate, price and margin, $m_{i}$, and the corresponding averages for the population of interacting rivals.

$$
\begin{aligned}
& \left.\left.g_{i}-g_{D}=\frac{\delta \mu}{\mu+b \delta} \mathbf{k}_{s}-h_{i}\right]+\frac{\delta}{\mu+b \delta} \mathbf{E}_{s}-\phi_{i}\right] \\
& p_{i}-\bar{p}_{s}=\frac{\mu}{\mu+b \delta}\left[\overline{\boldsymbol{h}}_{i}-\bar{h}_{s}\right]+\frac{1}{\mu+b \delta}\left[\boldsymbol{\phi}_{i}-\bar{\phi}_{s}\right] \\
& \left.\left.m_{i}-\bar{m}_{s}=\frac{\delta b}{\mu+b \delta} \bar{h}_{s}-h_{i}\right]+\frac{1}{\mu+b \delta} \oint_{i}-\bar{\phi}_{s}\right]
\end{aligned}
$$

In each case, the way the secondary measure of variation is related to the underlying primary measures depends explicitly on the way in which capacity growth and market growth are coordinated. To change this manner of coordination also changes the emergent phenomena; growth patterns depend on the way that markets work. Equation (4) forms a system of nonlinear coupled differential equations for the evolution of the market shares of the different companies. In general, they do not have an analytic solution, 
being closely related to the predator prey equations of a Lotka-Volterra system. We shall see below, however, that (4) in combination with (5) or (6) allows us to deduce expressions for the time variation of the moments of various population distributions.

Focus now on the distribution of growth rates (4). This tells us that the growth rates of the companies emerge jointly, they are interdependent, and it tells us how growth rate diversity depends on the distribution of unit costs and investment propensities around the population means. A company may be more efficient than average, $h_{i}<\bar{h}_{s}$, but it may grow less quickly than average if it has a co-joint lower than average propensity to invest $\left(\phi_{i}>\bar{\phi}_{s}\right)$. Patterns of growth, in general, depend on the joint distribution of selective characteristics.

Now the focus of these observations is that when growth rates differ, the structure of the economy is changing, resources are shifting between companies, absolutely and relatively. The economy is being transformed, it is in a state of flux, and in the process this is changing the average efficiency with which resources are utilised even when we abstract from the development process.

At this point we get to the core of the selection dynamic, for (4) is a replier equation ((5) and (6) are clearly not), the difference $g_{i}-g_{D}$ measuring the rate of growth of that company's market share. When market shares change, so do the population means $\bar{h}_{s}$ and $\bar{\phi} s$, to redefine the distribution of growth rates. The rates of change in these population means obey what I have called else where Fisher's Principle, after the eminent English geneticist who hit upon this general evolutionary principle in the 1930s (Fisher, 1930; Metcalfe, 1998). From the definitions of $\bar{h}_{s}$ and $\bar{\phi}_{s}$ it follows immediately that

$$
\begin{aligned}
\frac{d \bar{h}_{s}}{d t} & =\sum \frac{d s_{i}}{d t} h_{i}=\sum s_{i}\left(g_{i}-g_{D}\right) h_{i} \\
& =C_{s}(h, g)
\end{aligned}
$$

and similarly,

$$
\frac{d \bar{\phi}_{s}}{d t}=C_{s}(\phi, g) \text {. }
$$


For the average values of the selective characteristics to change they must co-vary statistically with the growth rates of the company! No correlation means no evolution. But we can go further because from (4) it follows that

$$
C_{s}(h, g)=-\Delta V_{s}(h)-\lambda C_{s}(\phi, h)
$$

and

$$
C_{s}(\phi, g)=-\lambda V_{s}(\phi)-\Delta C_{s}(\phi, h)
$$

where $\Delta=\frac{\delta \mu}{\mu+h \delta} \quad$ and $\quad \lambda=\frac{\delta}{\mu+h \delta}$ are the selection coefficients for the evolutionary process, and $V_{s}(\phi)$ is the variance in propensities to invest, and $C_{s}(\phi, h)$ is their covariance. In each case these statistics are computed using the market share weights, $s_{i}$, so that these measures of variation also evolve over time.

Thus, the replier dynamic captures well the idea of 'restless capitalism', the continued change in structure driven by micro-diversity in the presence of a market process.

Much more can be said about (4), (5) and (6) but space precludes doing so. Suffice it to state that they are a basis for evolutionary simulation and for econometric tests of the Fisher's Principle.

\section{The development process}

Instead, let us turn to the question of the development process. As without development, the process defined in (4) eventually grinds to a halt as the entire market becomes concentrated on the most dynamically viable of the companies. To ensure the sustainability of the transformation process, we need ongoing innovation and this comes from development. In our case this is subsumed in the technical progress functions of each company. The economist will recognise these as a representation of the Kaldor/Verdorn principle of dynamic increasing returns. 
The consequence of this hypothesis is to couple together selection and development. Rates of innovation depend upon rates of growth and rates of growth are determined in the selection process thus selection shapes innovation and in turn innovation reshapes the selection process. The consequence of this is that the innovative performance of any company cannot be separated from its current efficiency and its investment behaviour, nor can it be separated from the efficiency and investment rules of its rivals. Rates of innovation too are emergent phenomena.

To make this more transparent let us focus on the evolution of one statistic in our population, namely, the rate of change of $\bar{h}_{s}$. This is our measure of the average rate of development. Since $h_{i}=w a_{i}+b R$ it follows that, at given market shares,

$$
\left.\frac{d}{d t} \log \bar{h}_{s}\right|_{s_{i}}=\left.\bar{\omega} \frac{d}{d t} \log \bar{a}_{s}\right|_{s_{i}}
$$

where $\bar{\omega}$ is the average share of wage costs in total costs (not sales revenue) in the population of the companies.

Now it is simple arithmetic to establish that

$$
\begin{aligned}
\left.\frac{d}{d t} \bar{a}_{s}\right|_{s_{i}} & =\sum s_{i} \frac{d}{d t} a_{i} \\
& =-\sum s_{i}\left(\alpha_{i}+\beta g_{i}\right) a_{i}
\end{aligned}
$$

whence

$$
\left.\frac{d}{d t} \log \bar{a}_{s}\right|_{s_{i}}=-\left\{\frac{C_{s}(a, \alpha)+\beta C_{s}(a, g)}{\bar{a}_{s}}+\left(\bar{\alpha}_{s}+\beta g_{D}\right)\right\}
$$

This gives us the 'progress equation' for the population of companies holding constant their relative market positions. The term in the last bracket is the average progress effort dependent on $\bar{\alpha}_{s}$ and the growth rate of total output, $g_{D}$. These average effects are modified by two measures of micro-diversity: $C_{s}(a, \alpha)$, the covariance between efficiencies and idiosyncratic innovation rates, is a primary measure of variation, and $C_{s}(a, g)$ is a secondary, emergent measure. 
Now $C_{s}(a, g)=C_{s}(h, g)$ on our assumptions, and the latter co-variance we have already established above in our discussion of the selection process.

One step further, brings selection and development together. Since,

$$
\frac{d \bar{a}_{s}}{d t}=\sum \frac{d s_{i}}{d t} a_{i}+\sum s_{i} \frac{d a_{i}}{d t}
$$

we can write the combined effects of development and selection processes as:

$$
\frac{d}{d t} \log \bar{a}_{s}=-\left\{\frac{C_{s}(a, \alpha)-(1-\beta) C_{s}(a, g)}{\bar{a}_{s}}+\left(\bar{\alpha}_{s}+\beta g_{D}\right)\right\}
$$

In short, productivity grows in relation to the micro-diversity within the economy. The above account shows us how to combine together these different kinds of micro-diversity. The rate of productivity improvement depends on the market selection process in a fundamental way whenever we have companies characterized by dynamic increasing returns. Market processes do matter, but this cannot be represented in any framework that takes the aggregate economy as its starting point. Within this framework we have therefore established two points. First, that growth and innovation are coupled emergent phenomena. Secondly, that the average rate of progress depends upon the micro-diversity of the population as reflected in the correlations between efficiency and innovation and efficiency and growth.

\section{Conclusions}

In this paper we have reported on the first stages of our enquiry into an adaptive evolutionary approach to innovation growth and competition. We have emphasized the importance of structural transformation to the process of growth, the treatment of agent companies as bundles of decision-making routines, the importance of a population perspective and the treatment of economic growth as an emergent phenomena. We believe that this provides a radically different basis for a new understanding of economic growth and its 
relation with economic policy. We have also insisted on an evolutionary adaptive approach to economic growth, on the importance of micro diversity in relation to key economic behaviors, on the importance of the competitive process and, on the importance of depicting the economy as an evolving structure that is kept far from equilibrium by the continuous creation of novelty. In emphasizing the productive consequences of diversity we are necessarily questioning narrow notions of efficiency in the use of resources. A more sophisticated approach is required to recognize that creative, experimental processes involve the continuous generation of mistakes and from an ex-post point of view, the inefficient use of resources. This cannot be avoided in a knowledge driven economic system. As Peter Allen (2000) points out so perceptively, adaptive systems depend upon the presence within them of excess diversity.

New knowledge, its development and application, are central to this picture and it became clear to us that to analyse knowledge-based economies as if they are in a steady state equilibrium is not productive. Knowledge-based economies are restless economies and the more we disaggregate the more we find evidence for the changing dynamic order of modern capitalism. A concept of economic order is indispensable to any coherent account of adaptive evolution, and this requires that we treat seriously the institutions of markets and innovation systems and their evolutionary dynamic. This approach links naturally with capability-based theories of the company and other organizations and with theories of their internal evolution.

From a formal point of view the key issues involve the specification of selection and development dynamics in the relevant populations, and the rules for aggregating from the micro through to the macro. A simple model of agent companies, characterized by intrinsic rules of productivity, investment and innovative behavior and interacting in market-based selection environments enabled us to explore the dynamics of growth based on the Fisher Principles of evolutionary change. This perspective allows us to identify regularities in relation to growth of output and productivity and to demonstrate the interdependence of selection and development processes.

Of course, we have presented above a very partial picture of the growth process. The interaction between different market populations and the role of capital and labor markets, for example, needs to be specified more 
completely. There is also a clear empirical agenda before us to develop new measures of evolutionary change. Most importantly of all, there is the question of institutions, in our case, markets and distributed innovation processes, and the ways in which they can be said to evolve through processes of selection and development.

\section{Bibliography}

Allen, P., "Emergence and Design in Complex Systems" in McCarthy, I.P. and Rakatobe-Joel, T., (eds), Complexity and Complex Systems in Industry: Conference Proceedings, University of Warwick, 2000.

Arthur, B., Durlauf, S., and Lane, D., "Introduction", in Arthur, B., Durlaf, S., and Lane, D., The Economy as a Complex Adaptive System,II, Perseus Books, Reading, Mass., 1997.

Bailey, N.M., Hulten, C., and Campbell, D., "Productivity Dynamics in Manufacturing Plants”, Brookings Papers, Microeconomics, p. 187-267, 1992.

Baldwin, J.R., The Dynamics of Industrial Competition: A North American Perspective, Cambridge University Press, 1995.

Bartlesman, E.J. and Doms, M., "Understanding Productivity: Lessons from Longitudinal Microdata", Journal of Economic Literature, 2000. (forthcoming)

Blume, L., and Durlaf, S., "The Interactions Based Approach to Socioeconomic Behaviour", mimeo, Cornell University, 2000.

Brock, W. A., "Whither Nonlinear, Journal of Economic Dynamics and Control, 1999. (forthcoming)

Burns, A.F., 1938, Production Trends in the United States Since 1870, NBER, Boston, 1938.

Calderini, M., and Metcalfe J., S., "Chance, Necessity and Competitive Dynamics in the Italian Steel Industry", in Cantner, U., Hanusch, H., and Klepper, S., Economic Evolution, Learning and Complexity, Berlin, Springer Physica, 2000.

Depew, B., and Weber, D.J., Darwinism Evolving: Systems Dynamics and the Genealogy of Natural Selection, MIT Press, 1995. 
, and , "Natural Selection and Self-Organisation", Biology and Philosophy, v. 14, p. 33-65, 1999.

Dooley, K., and Corman, S., "Agent-Based Genetic and Emergent Computational Models for Complex Systems, mimeo, (LOCKS), University of Arizona, 2000.

Ebersberger, B., Canter ,U., and Hanusch, H., "Functional Search in Complex Evolutionary Environments - Examining an Empirical Tool", Paper presented to the $8^{\text {th }}$ International J.A. Schumpeter Society Conference, University of Manchester, June/July, 2000.

Eliasson, G., Firm objectives, Control and Organisation, Kluwer, Dordrecht, 1996.

Fisher, R., A., The Genetical Theory of Natural Selection, Oxford: Oxford University Press, 1930.

Foss, K. and Foss, N., Organising Economic Experiments: The Role of Firms, DRUID, WP no 995, Copenhagen Business School, 1999.

Foster, J., "Economics and the Self-Organization Approach: Alfred Marshall Revisited”, Economic Journal, v. 103, p. 975-991, 1993.

Foster, L., Haltiwanger, J. and Krizan, C.J., "Aggregate Productivity Growth: Lessons from the Micro Economic Evidence", NBER, WP 6803, Cambridge, 1998.

Frank, S.A., Foundations of Social Evolution, Princeton University Press, 1998.

Harberger, A., C., "A Vision of the Growth Process", American Economic Review, v. 88, p., 1-32, 1998.

Horan, B., "The Statistical Characçter of Evolutionary Theory", Philosophy of Science, v. 61, p.76-95, 1995.

Iwai, K., "Schumpeterian Dynamics Part II", Journal of Economic Behaviour and Organisation, v. 5, p., 321-351, 1974.

Jones, C.I., "RandD-based models of Economic Growth," Journal of Political Economy, v. 103, p. $759-804,1995$.

Kaldor, N., "A Classificatory Note on the Determinateness of Equilibrium", Review of Economic Studies, v. 1, p.122-136, 1934.

Kimura, M., "On the Change of population Fitness By Natural Selection", Heredity, v. 12 , p. $145-167,1958$.

Kirman, A.P., "Whom or What does the Representative Individual Represent?", Journal of Economic Perspectives, v. 6, n 2, p. 117 - 136, 1992. 
Kuznets, S.,1929, Secular Movements of Production and Prices, A. Kelly, (reprint) New York, 1929.

Langlois, R.N., "Systems Theory, Knowledge and the Social Sciences" in Machlup, F and Mansfield, U.(eds.), The study of Information, New York: Wiley, 1983.

Loasby, B., Knowledge, Institutions and Evolution in Economics, Routledge: London, 1999.

Machlup, F., "The Supply of Inventors and Inventions", in Nelson, R., (ed.) The Rate and Direction of Inventive Activity, NBER, Boston, 1962.

Malerba, F., Nelson, R., Orsenigo, G., and Winter, S., “'History Friendly' Models of Industry Evolution:The Computer Industry", Industrial and Corporate Change, v. 8, p.3-40, 1999.

Marshall, A., Industry and Trade, Macmillan: London, 1892.

Mayr, E., The Growth of Biological Thought, Harvard University Press, 1982.

Metcalfe, J.S., "The Design of Order: Notes on Evolutionary Principles and the Dynamics of Innovation”, Revue Economique, v. 46, p. 327-346, 1995. ,"Technology Strategy in an Evolutionary World", The Honeywell Sweatt Lecture In Technology Management, Institute of Technology, University of Minnesota, 1996. 1998.

Michod, R.E., Darwinian Dynamics, New Jersey: Princeton University Press, 1999.

Nelson, R., and Winter, S., An Evolutionary Theory of Economic Change, Harvard: Belknap, 1984.

"Why do Firms Differ and How Does it Matter", Strategic Management Journal, v.12, p.,61-74, 1991.

Penrose, E., The Theory of the Growth of the Firm, Oxford: Oxford University Press, 1958.

Phelps, E. and Winter, S., "Optimal Price Policy under Atomistic Competition", in Phelps, E.(ed.), Micro Foundations of Employment and Inflation Theory, W.W. Norton: New York, 1970. 
Polanyi, K., "The Economy as Instituted Process" in Polanyi, K., Arunsberg, C., and Pearson, H.W., Trade and Markets in the Early Empire Glencoe: Free Press, 1957.

Popper, K., A World of Propensities, Bristol: Thoemmes, 1985.

Prescott, E.C., "Needed: A Theory of Total Factor Productivity", International Economic Review, v. 39, no 3, pp.525-551, 1998.

Rosenberg, N., "Economic Experiments", Industrial and Corporate Change, v.1, p.181-204, 1992.

Saviotti, P., P., Technological Evolution, Variety and the Economy, London: Edward Elgar, 1996.

Sober, E., The Nature of Selection, Boston: MIT press, 1984.

Usher, D., The Measurement of Economic Growth, Oxford: Basil Blackwell, 1980.

Winter, S., Kaniovski, U.; Dosi, G., "Modelling Industrial Dynamics with innovative Entrants", Structural Change and Economic Dynamics, v.11, p, 255294, 2000.

Young, A.A., "Increasing Returns and Economic Progress, Economic Journal, v. 11, p. 527-542, 1928. 


\section{Appendix}

\section{Knowledge-Based Growth}

In a series of recent papers, Charles Jones has articulated a model of endogenous growth built around the idea of an ideas production function. The most important step taken by this work is to postulate a 'stock of ideas' that can be reduced to a quantity, $A$, and to argue that the change in this stock depends on the current stock and the level of research effort. As explained in the main text, this is effectively the argument of Machlup (1962). In this appendix we sketch this argument and test its robustness by asking "Can there be a steady-state growth of knowledge if we distinguish between different kinds of knowledge, say, science and technology?". The answer, special cases apart, is negative.

Jones proceeds as follows: Let there be a production function for ideas,

$$
\frac{d A}{d t}=\delta A^{\phi} L_{A}^{\lambda}
$$

where $L_{A}$ is the flow of labor applied to the generation of ideas and, $\delta, \phi$ and $\lambda$ are parameters defining the way in which knowledge leads to further knowledge, and the marginal product of research effort. Presumably, these parameters reflect the organization of the knowledge production process. In a steady state the rate of growth of the stock of ideas is required to be a constant,

$$
g_{A}=\frac{1}{A} \frac{d A}{d t}=\delta A^{(\phi-1)} L_{A}^{\lambda}
$$

Differentiating this expression and equating it to zero gives the required condition. A steady state is only possible if

$$
g_{A}=\frac{\lambda n}{1-\phi}
$$

Where $n$ is the rate of growth of research labor. In steady state this must be equal to the rate of growth of the total labor force also. Jones sets this equal to the rate of growth of population. 
If we postulate an aggregate production function $Y=A^{\sigma} L^{\alpha}$ it follows that

$$
g_{y}=\sigma g_{A}+\alpha g_{L}
$$

or

$$
g_{y}=\left(\frac{\sigma \lambda}{1-\phi}+\alpha\right) n,
$$

since $g_{L}=g_{L A}=n$ defines the steady state.

Now the important parameter in this is $\phi$, the elasticity of the increase in knowledge with regard to the stock of knowledge. If $\phi<0$ we have strong negative feedback (Machlup's agenda decreasing case). If $\phi<1$, we have Machlup's agenda increasing case. However, if $\phi>1$, we have agenda explosion, and a steady state for the production of knowledge is not possible.

\section{Science and technology}

A simple test for this framework is to abandon the idea of a single stock of ideas, and to distinguish, say, between science $\left(A_{S}\right)$ and technology $\left(A_{T}\right)$ each with their different knowledge production functions.

Thus, we could write

$$
g_{S}=\delta_{S} A_{S}^{\phi_{S}-1} A_{T}^{\phi_{T S}} L_{S}^{\lambda_{S}}
$$

and

$$
g_{T}=\delta_{T} A_{T}^{\phi_{T}-1} A_{S}^{\phi_{S T}} L_{T}^{\lambda_{T}}
$$

This formulation recognizes the interdependence between these two kinds of ideas via the elasticities $\phi_{S T} \neq \phi_{T S}$. Again we can presume that these parameters reflect the different ways of organising science and technology and the way they interconnect. Now a steady state for science and technology taken independently requires that $d g_{S} / d t=d g_{T} / d t=0$ This is only possible when

$$
g_{T}=\frac{1}{1-\phi_{T}}\left\{\lambda_{T} n_{T}+\phi_{S T} g_{S}\right\}
$$


and

$$
g_{S}=\frac{1}{1-\phi_{S}}\left\{\lambda_{S} n_{S}+\phi_{T S} g_{T}\right\}
$$

Clearly, the growth rates of the two kinds of knowledge are complementary. A greater growth rate of science implies a greater growth rate of technology and vice versa. Solving for the consistent growth rates we find that

$$
g_{T}=\frac{1}{\Delta}\left[\left(1-\phi_{S}\right) \lambda_{T} n_{T}+\lambda_{S} \phi_{S T} n_{S}\right]
$$

and

$$
g_{S}=\frac{1}{\Delta}\left[\left(1-\phi_{T}\right) \lambda_{S} n_{S}+\lambda_{T} \phi_{T S} n_{T}\right]
$$

and

$$
\Delta=\left(1-\phi_{T}\right)\left(1-\phi_{S}\right)-\phi_{S T} \phi_{T S}
$$

Clearly, $\Delta>0$ is required for a meaningful interpretation of these steady state relationships.

Now if the economy is to be in steady state, $n_{S}=n_{T}=n$, it follows that $g_{T} \neq g_{s}$ in general. The two stocks of knowledge cannot be growing at the same rate, a steady state for the growth of ideas is not possible. Conversely if we impose $g_{T}=g_{S}$ we will find, in general, that $n_{T} \neq n_{S}$, so we cannot have a steady state in the allocation of research effort.

A condition for a steady state is that $\phi_{T}=\phi_{S}=\phi_{S T}=\phi_{T S}$ but this is a trivial requirement for which there is no clear motivation.

Consequently, we conclude that the Jones approach does not generalize when we disaggregate different kinds of ideas and make these complements. It does not matter whether we distinguish kinds of knowledge or national locations of knowledge production, the idea of a steady state of knowledge accumulation is not coherent. 


\section{Bibliography}

Jones, C.I., "RandD-Based Models of Economic Growth", Journal of Political Economy, v. 103, p. 759-784, 1995.

Jones, C.I., "Growth: With or Without Scale Effects", American Economic Review, v. 99, (May), 1999.

Jones, C.I., "Was an Industrial Revolution Inevitable? Economic Growth over the Very Long Run”, mimeo, Stanford University, 2000. 